\title{
Ecotourism of Tropical Regions with Renewable Energy Perspective in Indonesia
}

\author{
Sindu Daniarta ${ }^{\mathrm{a}}$, Yose Ardhani Farasi ${ }^{\mathrm{a}}$ \\ ${ }^{a}$ Departement of Engineering Physics, Faculty of Engineering, Univeristas Gadjah Mada, Yogyakarta \\ Jl. Grafika No. 2, Yogyakarta 55281, Indonesia
}

\begin{abstract}
Indonesia is archipelago country with natural resources and population 230 million in 2010. The natural resources areas are mining, forestry, natural tourism. Indonesia has much natural tourism without electricity. At this time, the issues about electricity are growing rapidly. Renewable energy system is most contribution to generate electricity. Photovoltaic and wind turbine are usually for renewable energy system in tropical region. HOMER Energy software system is used to simulate the model of ecotourism with renewable energy system. In future can be used as a reference in the development of renewable energy based Ecotourism Island in Indonesia
\end{abstract}

Keywords : Ecotourism; HOMER Energy; renewable energy; wind turbine

\section{Introduction}

Indonesia is archipelago country with natural resources. Indonesia has a population of about 230 million in 2010. Wealth of natural resources affects the rate of economic growth and development. Some of resources can be used as an object of nature tourism. The tourism sector which is a multi-sector and multi-affect has the potential to generate a substantial income. Among the island, Java and Bali is the two most populated islands in the country, which have the most extensive electricity system. Electricity needs is very important which used for hospitality, lighting, restaurant and others. Electricity demand is linear with population growth. As other area are less populated, and often the population is located remotely in rural area or isolated in the smaller island, the electrification faces difficulties to provide electricity using conventional grid extension.

In Indonesia, rural area or isolated in a smaller island usually have a great environmental which have a potential of tourism. Based on the Destination Management Organization (DMO), there are several islands that became the superior product such us Sabang, Derawan, Bali, Bunaken, Wakatobi, Komodo and Raja Ampat archipelago. The islands are potential to become ecotourism which have relations in social-environmental-economic. Ecotourism is a method that gets impact for the country. This paper discuss how to improving ecotourism with renewable energy perspective in Indonesia.

\footnotetext{
* Corresponding author. Tel.: +62 85725773452.

E-mail address: sindu.daniarta@gmail.com
} 


\section{Method}

This paper look at the facts about methods that have been used to overcome the problems occurred in the electrification of tourism islands of Indonesia. By designing the system, scenarios, different conditions, this paper want to determine the optimal configuration of electrification system with hybrid renewable energy system in tourism area of Indonesia.

\subsection{Ecotourism}

Ecotourism concerns travel to a natural area; involving local people; feeding economic profit into local environmental protection; and contributing to the maintenance of local environment and species diversity trough minimizing visitor impact and promoting tourist education [1]. Definitions of ecotourism cohere around three criteria (i) attractions should be predominantly nature-based, (ii) visitor interactions with those attractions should be focused on learning or education, and (iii) experience and product management should follow principles and practices associated with ecological, socio-cultural and economic sustainability. Ecotourism is built with a three element, there are social, economic and environmental. The bottom of social, economic and environmental relations is called elements of triple-bottom-line-sustainability (TBLS) [2].

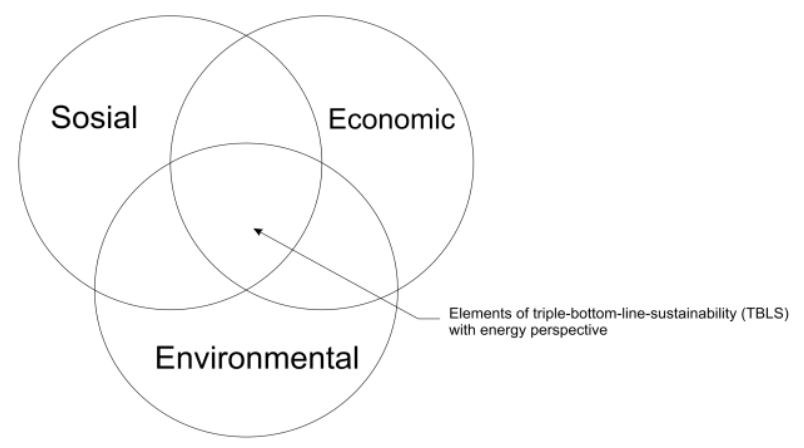

Figure 1. Elements of triple-bottom-line-sustainability (TBLS) with energy perspective.

Energy is supplied to tourism resort destinations through a series of extraction, conversion, and distribution system. Energy use in tourism destination is normally disproportionately greater than what is typically associated with other similar sized communities. Usually, energy is used for cooking, heating, air conditioning, cooling, cleaning, and lighting. In many tropical or arid regions, energy is also needed for the desalination of seawater. A substantial quantity of energy is also required to construct new infrastructure, accommodations and other facilities.

\subsection{Hybrid renewable energy systems}

Hybrid power systems usually integrate renewable energy source to provide electrical power. They are generally independent of large centralized electric grids and are used in remote areas. In these systems, it is possible for the individual power sources to provide different percentages of the total load. In Indonesia, hybrid renewable energy system is most effectively because of its potentials. The potential are solar energy and wind energy. Table 1 describes the potential map of solar energy and wind energy in Indonesia. The advantages of using renewable 
sources for generating power in remote areas are obvious. Table 1 show the characteristic renewable energy source in Indonesia. Indonesia has $5.34 \mathrm{kWh} / \mathrm{m} 2 / \mathrm{d}$ daily solar radiation-horizontal and $4.6 \mathrm{~m} / \mathrm{s}$ wind speed. This potential can be transformed into the electricity with photovoltaic and wind turbine.

Table 1. Meteorology and solar energy: RET screen data in Indonesia.

\begin{tabular}{lccccc}
\multicolumn{7}{c}{ Table 1. Meteorology and solar energy: RET screen data in Indonesia. } \\
\hline \multirow{2}{*}{ Month } & Air temperature & Relative humidity & $\begin{array}{c}\text { Daily solar } \\
\text { radiation }- \\
\text { horizontal }\end{array}$ & Wind speed & Earth temperature \\
\hline January & ${ }^{\circ} \mathrm{C}$ & $\%$ & $\mathrm{kWh} / \mathrm{m}^{2} / \mathrm{d}$ & $\mathrm{m} / \mathrm{s}$ & ${ }^{\circ} \mathrm{C}$ \\
\hline February & 25.8 & $80.4 \%$ & 5.20 & 7.0 & 26.0 \\
March & 25.8 & $81.0 \%$ & 5.96 & 5.5 & 26.3 \\
April & 26.4 & $80.4 \%$ & 6.59 & 4.7 & 27.5 \\
May & 27.3 & $79.8 \%$ & 6.68 & 3.2 & 29.1 \\
June & 27.8 & $80.1 \%$ & 5.76 & 2.8 & 29.9 \\
July & 27.8 & $79.6 \%$ & 4.97 & 4.4 & 29.8 \\
August & 27.6 & $79.2 \%$ & 4.78 & 4.3 & 29.4 \\
September & 27.6 & $79.2 \%$ & 4.99 & 4.7 & 29.2 \\
October & 27.4 & $79.3 \%$ & 4.96 & 4.0 & 29.2 \\
November & 27.0 & $81.9 \%$ & 4.76 & 3.4 & 29.1 \\
December & 26.6 & $82.6 \%$ & 4.81 & 4.9 & 28.0 \\
Annual & 26.2 & $80.6 \%$ & 4.57 & 7.0 & 26.6 \\
\hline
\end{tabular}

\subsection{Design systems}

Systems of hybrid renewable energy system are designed as shown Figure 2.

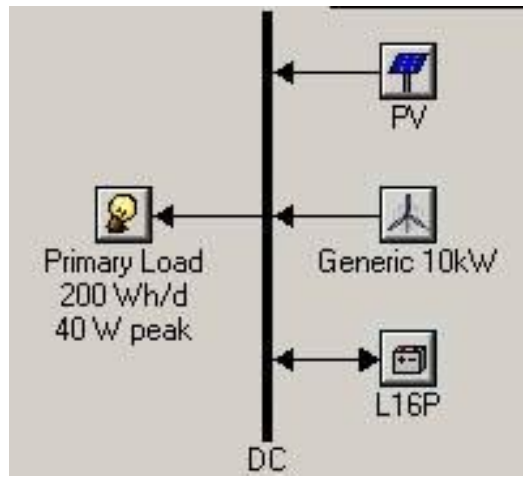

Figure 2.Design system hybrid renewable energy system.

\subsubsection{Primary load}

Agriculture and fisherman is the main economic activity in remote rural village. They also are in the small island which has a tourism area. In the night, electricity is available from 18:00 to 06:00 for household sector and tourism. 


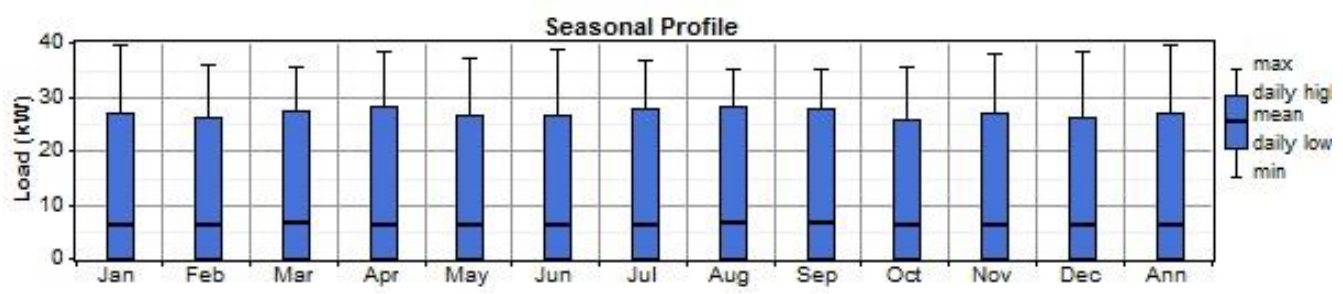

Figure 3. Seasonal profile per month.

Loading profile in rural area or small island has specifications in baseline $(160 \mathrm{kWh} / \mathrm{d}, 6.67 \mathrm{~W}, 39.7 \mathrm{~kW}$ of peak, and 0.168 of load factor) and scaled $(.0 .200 \mathrm{kWh} / \mathrm{d}, 0.00833 \mathrm{~W}, 0.0400 \mathrm{~W}$ of peak, and 0.208 of load factor).

\subsubsection{Wind turbine}

Overall wind energy potential of Indonesia is not great. Based on surveying and measurement of wind data, it has been done since 1979. Many prospective areas for wind speeds annual (3.4 to 4.5$) \mathrm{m} / \mathrm{s}(200 \mathrm{kWh} / \mathrm{m}$ to 1000 $\mathrm{kWh} / \mathrm{m}$ ). This potential can already be used for small-scale electricity generation to $10 \mathrm{~kW}$. The characteristic of generic type $10 \mathrm{~kW}$ can be seen from table B. Capital cost is USD 1200 . Replacement cost is USD 1100. Operational and maintenance cost is USD 20.

\subsubsection{Photovoltaic}

Photovoltaic $(1 \mathrm{~kW})$ has a capital cost and replacement cost. The capital cost is USD 8000 . The replacement cost is USD 7 000. Operational cost and maintenance cost can be assumed to be zero because the PV does not require specific maintenance. Figure 4 shows PV inputs. 


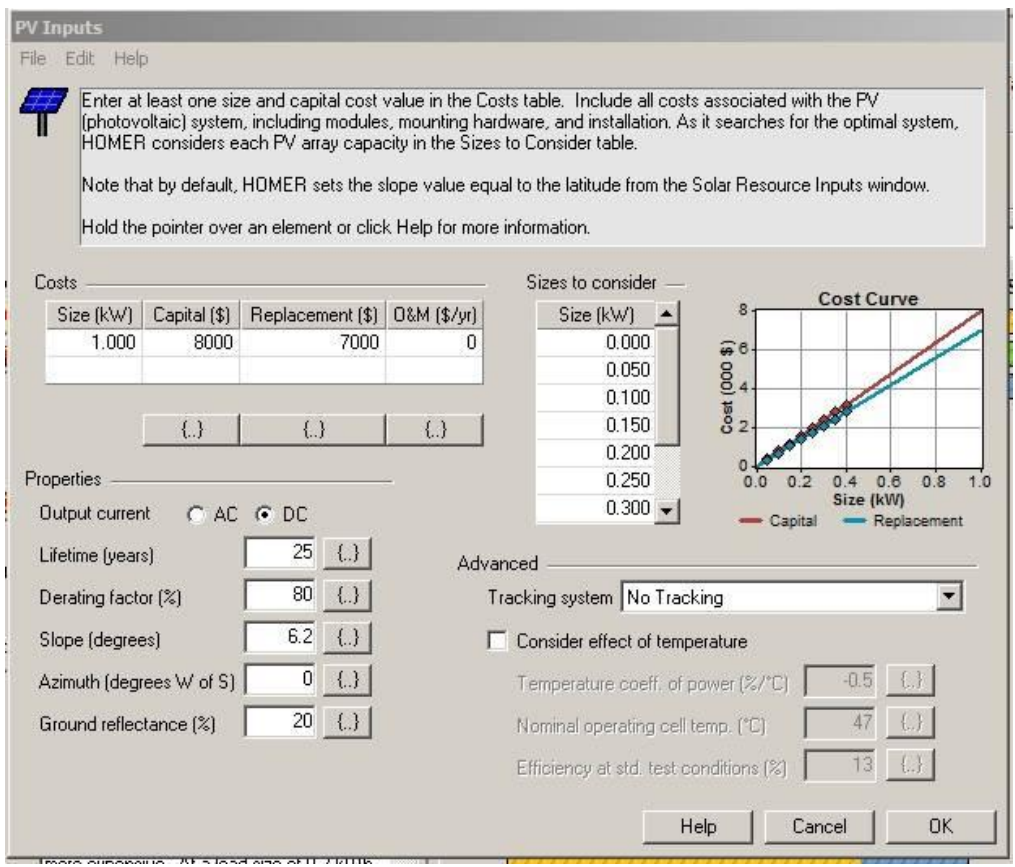

Figure 4. PV Inputs.

\subsubsection{Battery}

Assuming constant properties and affected by external factors such as temperature, battery work 24 hours. Batteries are used Trojan L16P with the characteristic of having a voltage of $6 \mathrm{~V}, 360 \mathrm{Ah}$ at the 20 hour rate and $2.16 \mathrm{kWh}$. The price of battery is estimated USD 130, USD 117 replacement cost, and USD 4 O \& M costs.

\section{Result and discussion}

This paper use PV array $(0.1 \mathrm{~kW})$, wind turbine (1 generic $10 \mathrm{~kW})$, and battery (2 trojan L16P). Figure 5 shows montly average electric production using PV and wind turbine.

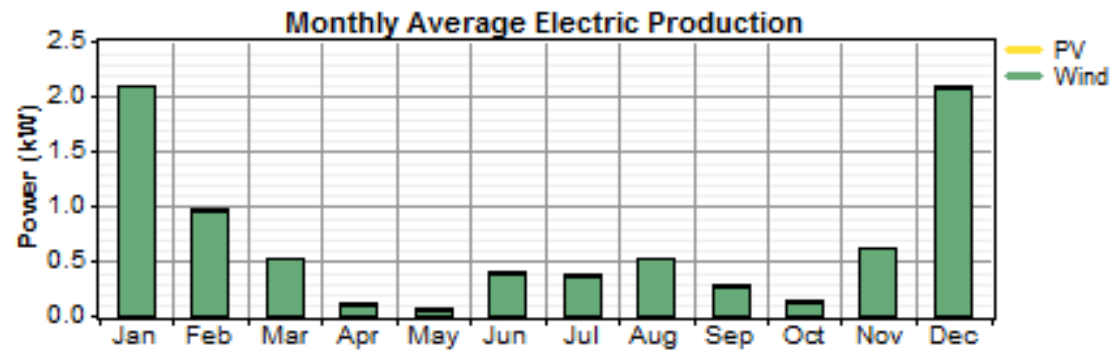

Figure 5. Montly average electric production. 


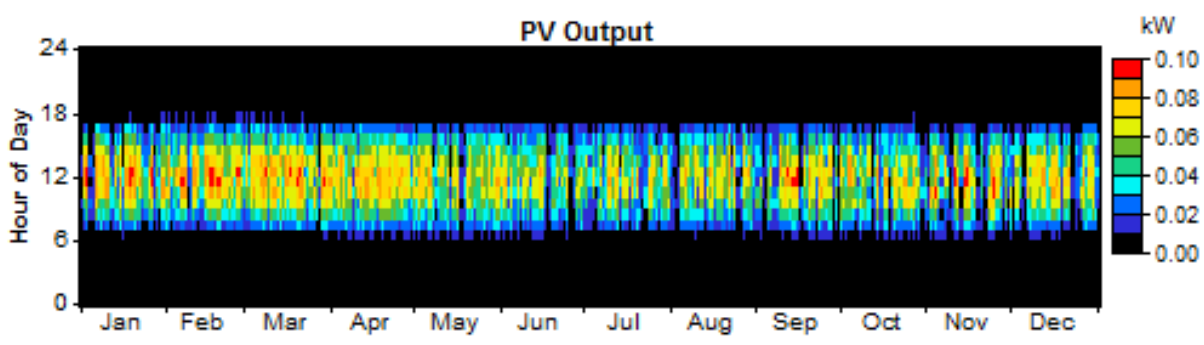

Figure 6. PV output in hour of day (monthly).

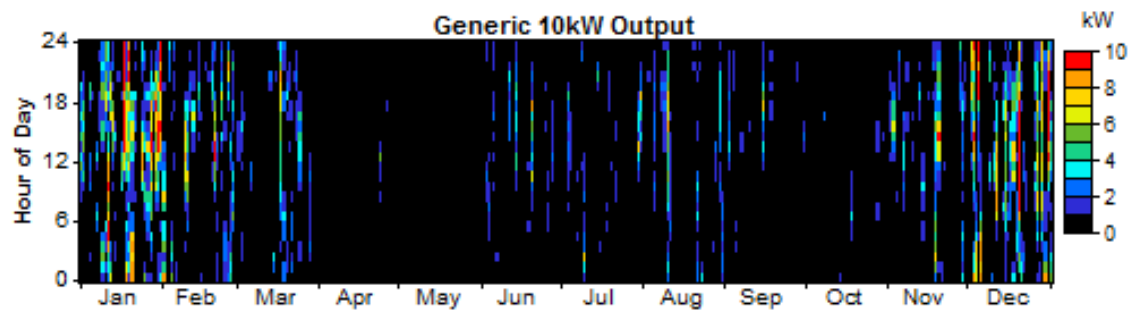

Figure 7. Wind turbine output in hour of day (monthly).

Figure 6 shows the PV output in monthly. Figure 7 shows the wind turbine output in monthly. Each device has an characteristic of device output because of the potential. PV can generate electrical energy around $0.428 \mathrm{~kW} / \mathrm{d}$. Wind turbine can generate energy output of $0.668 \mathrm{~kW} / \mathrm{d}$. So, the total of generating electrical energy is $1.096 \mathrm{~kW} / \mathrm{d}$. This is in conformity with the case sensitivity of the proposed system with the primary load average scaled $1 \mathrm{kWh} / \mathrm{d}$. The design of the system optimization of this system is showed in Figure 6.

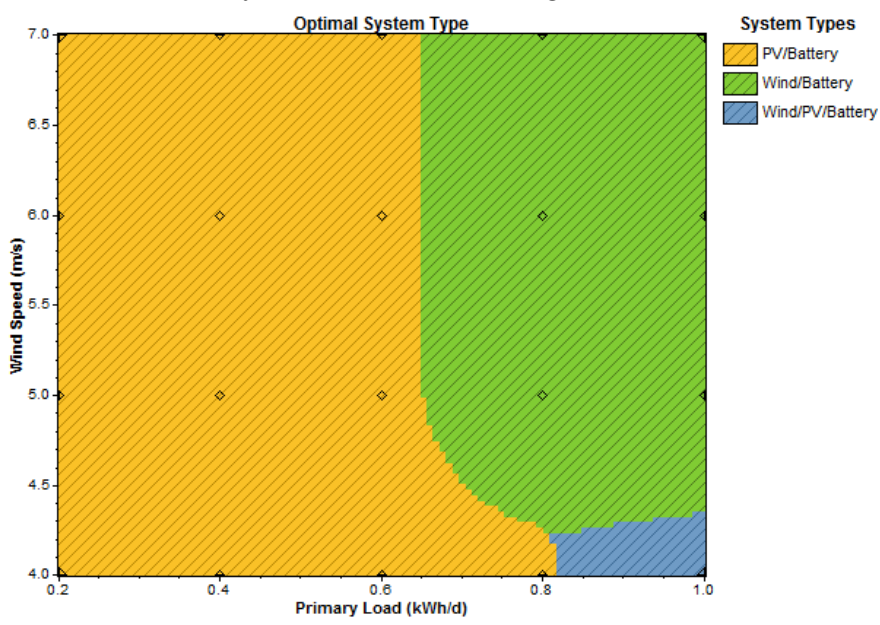

Figure 8. Results of system optimization.

It can be seen from the area in the Figure 5 where the system works with combination PV and wind turbine. This case needs to be considered in term of funding. Where the system with PV or battery has the lowest cost compared to other systems. The total net present cost of USD 1787 followed by wind or battery USD 2142 . For system of wind, PV, and battery have a total net present cost of USD 2 520. Using PV, wind turbine, and batter can 
reduce the greenhouse effect of conventional fuels. Utilizing this technology can eliminate pollutant such as carbon dioxide, carbon monoxide, unburned hydrocarbons, sulfur dioxide, and nitrogen oxides.

\section{Conclusion}

Environmental, economic, and social can be achieved through the provision of hybrid renewable energy system. This systems allow to convert fossil energy consumption into renewable energy. Doing modeling hybrid systems obtained optimization system is a hybrid system in which the model is obtained with PC and wind turbine. Energy and ecotourism has a relations that has three indicators. The indicators are social, environmental and economic. The role of energy in field of social, community using renewable energy is to increase the value of their existing local resources.

In the environmental field already known that this system doesn't use conventional fuels. So, there are no emission from the systems. In the field of business, the hybrid renewable energy system is suitable for the development of ecotourism areas. So, the application of this plant is a sustainable business model. Using a hybrid renewable energy system can make a sustainable ecotourism for public especially in archipelago or small island .

\section{References}

[1] Blum NU, Sryantoro, Wakeling R, Schmidt T. Rural electrification through village grids - Assessing the cost competitiveness of isolated renewable energy technologies in Indonesia. Renewable and Sustainable Energy Reviews 2013; 22, 482-496.

[2] Girona, Moner. A new scheme for the promotion of renewable energies in developing countries: the renewable energy regulated purchase tariff. JRC European Commission 2008.

[3] Hill J, Gale T. Ecotourism and environmental sustainability. Burlington: Ashgate Publising Company. 2009

[4] Kazem, HA, Khatib T, Sopian K. Sizing of a standalone photovoltaic/battery system at minimum cost for remote housing electrification in sohar, Oman. Energy and Buildings 2013; 61, 108-115

[5] Lilienthal P. Getting started guide for HOMER Version 2.1 National Renewable Energy Laboratory. 2005

[6] Ma T, Yang H, Lu L. A feasibility study of stand-alone hybrid solar-wind-battery system for a remote island. Applied Energy 2014; 121:149159. 